Proc. Estonian Acad. Sci. Eng., 2003, 9, 2, 137-147

\title{
Formation of aerosol particles by low-frequency sound-stimulated combustion
}

\author{
Veera Dushenko ${ }^{\mathrm{a}}$, Medhat Hussainov ${ }^{\mathrm{a}}$, Igor Shcheglov ${ }^{\mathrm{a}}$, \\ and Toomas Tiikma ${ }^{\mathrm{b}}$ \\ a Estonian Energy Research Institute, Tallinn Technical University, Paldiski mnt. 1, 10137 Tallinn, \\ Estonia; aeromeh@online.ee \\ b Thermal Engineering Department, Tallinn Technical University, Kopli 116, 11712 Tallinn, \\ Estonia; tiikma@sti.ttu.ee
}

Received 27 October 2000, in revised form 18 March 2003

\begin{abstract}
This paper presents the results of an experimental study of the formation of aerosol particles at the outlet of a flue gas duct of power equipment under the influence of low-frequency sound fluctuations (acoustic field) by burning a gaseous fuel. To measure the concentration and velocities of the aerosol particles in the flue gas, a laser Doppler anemometer, adapted to the conditions of the test rig, was used. The applied technique allowed to detect signals of solid aerosol particles with a size of 4-70 $\mu \mathrm{m}$ directly in a flue gas duct. In our experiments the existence of particles with a size over $40 \mu \mathrm{m}$ was not detected. That is, there were no large agglomerates of aerosol particles in the flow. Besides, the study of aerosol particles enabled us to explain the increased content of $\mathrm{CO}$ because of the $\mathrm{CO}_{2}$ decay. Thus, monitoring of aerosol particles allowed to receive additional information about the combustion process.
\end{abstract}

Key words: combustion, low-frequency sound fluctuations, aerosol particles, LDA.

\section{INTRODUCTION}

During the combustion process in power equipment either emergence of condensed (formed by the volumetric condensation of over-saturated vapours or as a result of chemical reactions) or dispersed (by dispersion of solid and liquid materials) aerosols is possible. There is a lack of sufficient information about the formation of aerosol particles and their possible agglomerates at the outlet of flue gas ducts of power equipment, about the particle size, concentration, and velocities. Study of the formation and behaviour of solid aerosol particles with the size of $2-50 \mu \mathrm{m}$ is of great interest $\left[{ }^{1,2}\right]$. The cyclones for cleaning flue gas after the 
furnaces of circulated fluidized bed boilers cannot catch these particles, and therefore ash deposits may precipitate on the convective heat transfer surfaces.

The quantity and structure of aerosol particles formed in the process of combustion depends substantially on the specific combustion conditions. The acoustic influence is one of the ways to optimize combustion processes. A sonically stimulated combustion process shows several simultaneous specific effects. Namely, imposition of a low-frequency $(40-100 \mathrm{~Hz})$ sound field improves mixing of the burning material in the flow and thus promotes complete combustion and improves heat transfer. Thus a reduction of the flame length results $\left[{ }^{3-5}\right]$. Besides, the high-intensity sound field can create agglomerations of soot particles $\left[{ }^{6,7}\right]$, thus increasing the radiation extinction coefficients both of spectral and total radiation $\left[{ }^{7}\right]$. The authors of $\left[^{7}\right]$ note that this phenomenon can be neglected in heat transfer. However, while the flame emissivity increases, substantial effect of flame radiation can be observed and must be taken into account $\left[{ }^{5}\right]$. The decrease of temperature at certain points of the flame, in spite of the increase of the combustion intensity and diffusion and constant fuel rate, may be caused by sonic simulation of the combustion process itself. It can be explained by additional turbulization of the burning flow that leads to the increased heat transfer from the flame to the surroundings. Monitoring of the aerosol particles formed in these processes has enabled us to get additional information for the analysis of the combustion process.

The purpose of present investigation is to study experimentally the impact of low-frequency sound fluctuations on the combustion of natural gas and formation of aerosol particles and their agglomerates in this process.

\section{DESCRIPTION OF THE LDA TECHNIQUE AND DATA PROCESSING}

The experiments were carried out on the test rig described in $\left[{ }^{3,5}\right]$. For measuring the concentration and velocities of aerosol particles in flue gas, the laser Doppler anemometer (LDA) technique adapted to the specific conditions of the given experiment was used. The counting concentration of aerosol particles during the combustion process was determined by recording the time of particle entry into the LDA measuring volume. The particles were recorded by LDA at the axis of the flue gas duct of $30 \times 30 \mathrm{~mm}$ cross-section at the distance of $2 \mathrm{~m}$ from the burner outlet. Also the fuel gas and air consumption, temperature, and composition of the flue gas were measured.

\subsection{Optical scheme and measurements}

A forward-scattering LDA was used to determine the instantaneous velocities and for counting the concentration of particles (Fig. 1). The LDA transmitting unit with a $26 \mathrm{~mW}$ laser formed the measuring volume with dimensions sufficient to record the velocities of micron-size particles. The receiving unit 


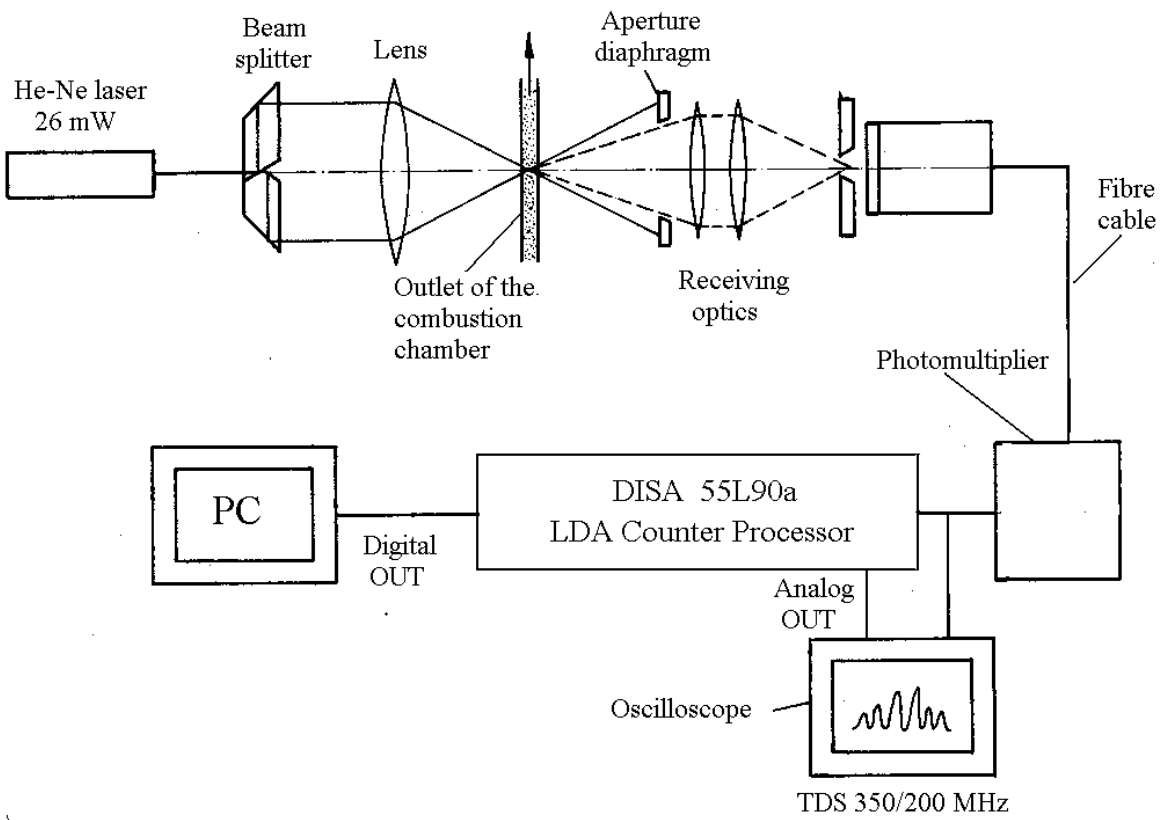

Fig. 1. Architecture of the LDA equipment.

(Fig. 1) consisted of the receiving optics, fibre cable, and photomultiplier (PM) and was tuned to recording signals from the particles with a size of about 4-70 $\mu \mathrm{m}$. The LDA system has a modular structure, and hence, it was easy to get access to the system and adjust the optical set-up according to the experimental requirements.

The dependence of Doppler signals on particle properties and parameters of the LDA system was used for tuning the LDA to provide reliable detection and separation of Doppler signals from the particles of specific size. The receiving conditions and sensitivity of the LDA system were selected on the basis of preliminary experimental investigations for optimal recording of Doppler signals from various groups of particles: 4-20, 15-30, 25-35, 32-40, 37-45 $\mu \mathrm{m}$, etc. Tuning of the LDA for recording signals from the particles of given groups was based on the Babinet's principle and carried out by a special simulator for giving small receiving angles where the diffraction component of scattered laser radiation was predominant. This simulator was a rotating disc, on which a piece of foil with micron holes was fixed. The diameter of these holes corresponded to the size of aerosol particles.

A signal from the LDA photomultiplier was transferred to the counter, which analysed its quality and transferred the obtained velocity of particles that had passed the measuring volume, to the computer. The signals from large particles of different size were rejected automatically either by the amplitude discrimination as saturated signals (Fig. 2), or by the depth modulation with the help of the counter $\left[{ }^{8}\right]$. A specific software for these LDA measurements was used; it consisted of various subroutines for the data collection and analysis. 


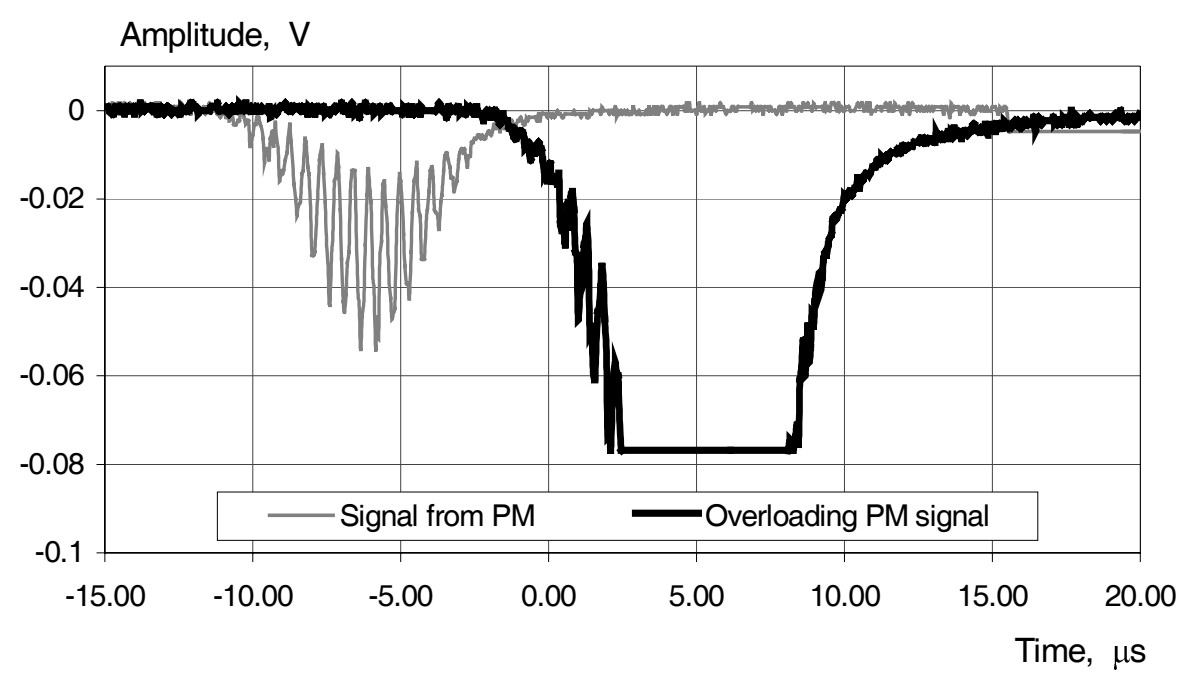

Fig. 2. The PM signals from particles of the size of $4-20 \mu \mathrm{m}$ and those larger than $20 \mu \mathrm{m}$ (overloading).

\subsection{Determination of the velocity}

The particle mean velocity and fluctuating velocity components were determined from 100-500 recordings of instant velocities. Such a small number of recordings was due to the low concentration of particles in the flue gas. The duration of one recording session was up to 3 min for the stabilized combustion regime. The mean velocity of particles and fluctuating velocity components were estimated as follows $\left[{ }^{9}\right]$ :

$$
\begin{gathered}
\bar{u}=\frac{N}{\sum_{i=1}^{N} \frac{1}{u_{i}}}, \\
\sigma=\sqrt{\frac{1}{N} \sum_{i=1}^{N}\left(u_{i}-\bar{u}\right)^{2}},
\end{gathered}
$$

where $u_{i}$ is the instant value of particle velocity and $N$ is the number of recordings.

The aerosol 4-20 $\mu \mathrm{m}$ particles are well entrained by the gas flow, and therefore the given group of particles traces the turbulent motion of gas $\left[{ }^{10}\right]$. For the present investigation the turbulence rate $T u$ is defined as classical turbulence - the ratio of fluctuation to the mean velocity:

$$
T u=\frac{\sigma}{\bar{u}} \times 100 \% \text {. }
$$


Table 1. Dependence of $K u$ on the Reynolds number $R e$

\begin{tabular}{c|c}
\hline$R e$ & $K u$ \\
\hline 2800 & 1.10 \\
2950 & 1.16 \\
3000 & 1.18 \\
3200 & 1.46 \\
3370 & 1.44
\end{tabular}

Table 2. Dependence of $K u$ on the turbulence rate $T u$

\begin{tabular}{c|c}
\hline$T u, \%$ & $K u$ \\
\hline 13.00 & 1.10 \\
25.64 & 1.16 \\
27.00 & 1.18 \\
34.39 & 1.46 \\
38.38 & 1.44
\end{tabular}

It is essential to know the properties of turbulent flow in the duct to study the behaviour of aerosol particles. The coefficient $K u$, which is the ratio of the velocity at the duct axis to mean velocity in the duct, characterizes the flow field. As it is well known, for the developed turbulent channel flow this ratio is 1.26 for the Reynolds number $R e=5 \times 10^{3}\left[^{11}\right]$. In the given experiments for $R e=(2.5-$ $3.5) \times 10^{3}, K u$ varies in the range of 1.05-1.45 (Table 1). This confirms that the velocity distribution across the channel does not correspond to the turbulence developed by an external source, the sonic generator (Table 2). Thus, there is an essential need for establishing the velocity distribution to determine the concentration of aerosol particles in the flue gas correctly.

\subsection{Determination of the particle concentration}

The counting method was used for determining the concentration of aerosol particles in the selected volume of flue gas. The time instant of receiving a signal from each particle in the LDA channel was recorded. Here we assumed that the flow of particles was characterized by the constant mean density, and therefore the results of particle counting obeyed the Poisson distribution $\left[{ }^{12,13}\right]$. The technique of data processing consisted of standard procedures $\left[{ }^{14}\right]$. The fixed characteristics of the Poisson distribution allow to calculate the concentration of aerosol particles in the selected volume of flow for every combustion regime.

As an example, the data processing for one test run, in which the duration of observation was $284 \mathrm{~s}$ and the number of the recorded particles was 100 , is considered. Let the observation interval be 10 s. Figure 3 shows the results of 28 observations. For the given example the most probable number of recordings equals 4 . Since the interval equals $10 \mathrm{~s}$, the value of 0.4 particles per second can be accepted for counting the particle concentration by the given combustion 


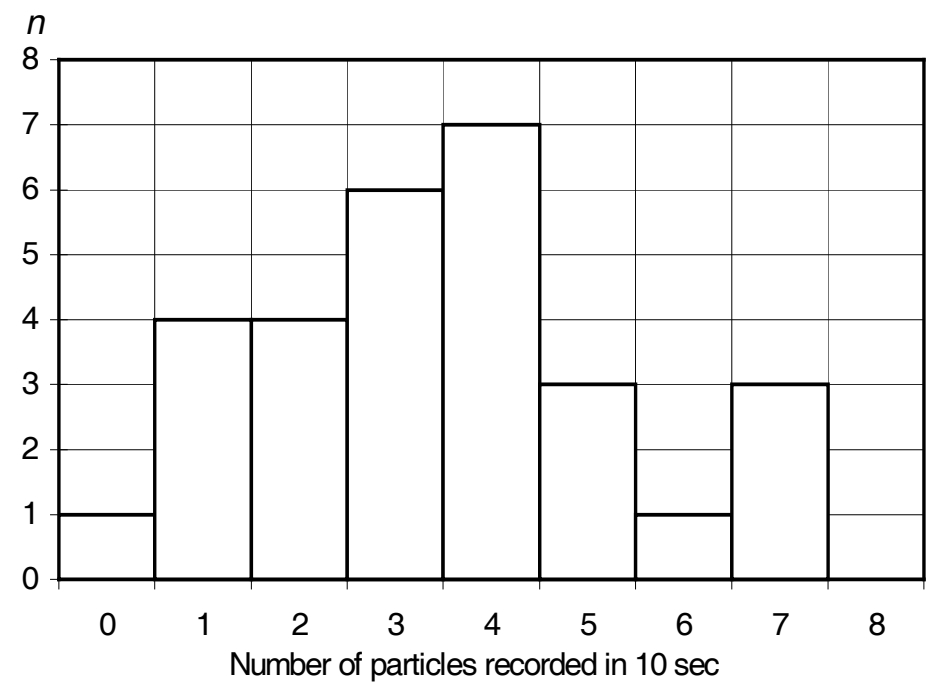

Fig. 3. Histogram of the number of recordings, $n$.

regime. For counting the particle concentration and the known area of the crosssection of LDA measuring volume, perpendicular to the gas flow, the flow density of aerosol particles can be calculated. Based on the flow density and mean velocity, we can estimate the numerical concentration of particles.

\section{EXPERIMENTAL PROCEDURE AND RESULTS}

In the experiments the following parameters were recorded: the fuel gas and air consumption, the flue gas composition $\left(\mathrm{O}_{2}, \mathrm{CO}, \mathrm{NO}_{\mathrm{x}}\right)$, velocity and concentration of aerosol particles, and temperature level at the characteristic points of the test rig (in flowing gases, on the walls and heat exchange surfaces).

Natural gas was burnt with the sonic stimulation at a considerably high excess air rate $(1.25-1.4)$ in the frequency interval $40-70 \mathrm{~Hz}$ with the intensity up to $140 \mathrm{~dB}$ (natural sound level due to the flame and air vents was about $110 \mathrm{~dB}$ ). A high level of the excess air rate was used to support stable combustion by the active (high intensity) sonic stimulation.

In the experiments the sound fluctuations improve mixing in the flow through turbulization of the gaseous medium. Due to this phenomenon, the turbulence rate depends on the intensity of sound oscillations (Fig. 4) and can be accepted as a generalized parameter of the studied process. As it is known, the turbulence rate is mainly related to the amplitude of medium fluctuations. The amplitude depends linearly on the acoustic pressure at the given frequency. That means exponential dependence of the turbulence rate on the sound intensity. In our experiments, the LDA set-up was tuned for the signal detection from the particles of different size. Figure 5 shows typical distribution of the counting concentra- 


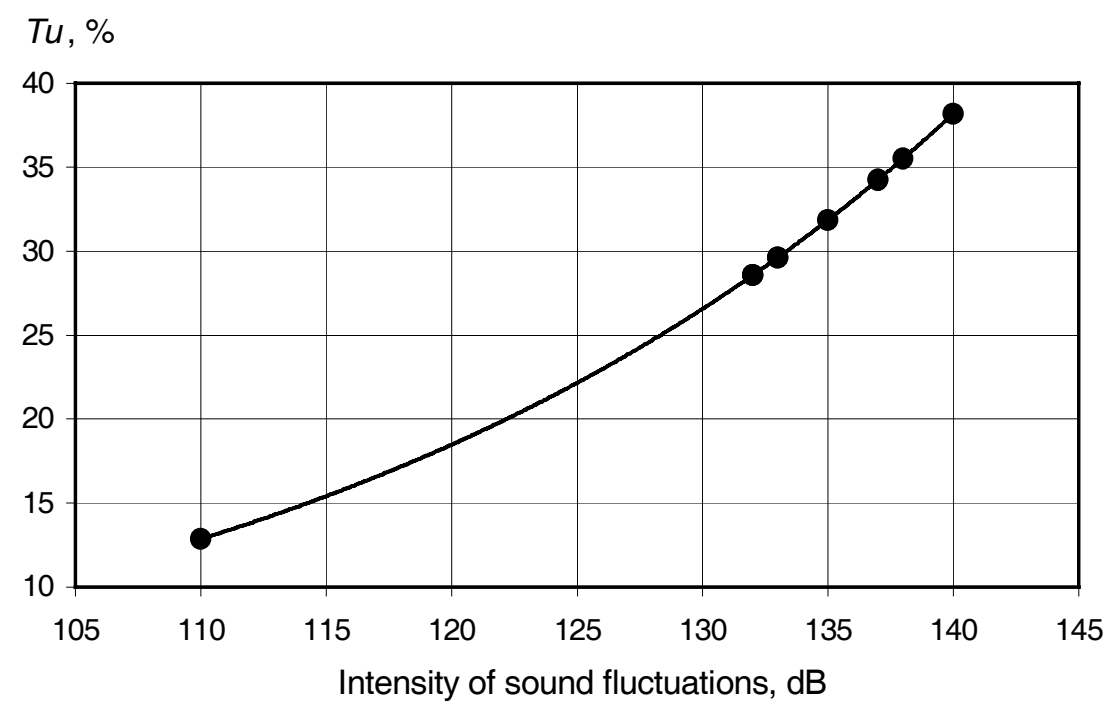

Fig. 4. Dependence of the turbulence rate on the intensity of sound fluctuations at the frequency of $40 \mathrm{~Hz}$.

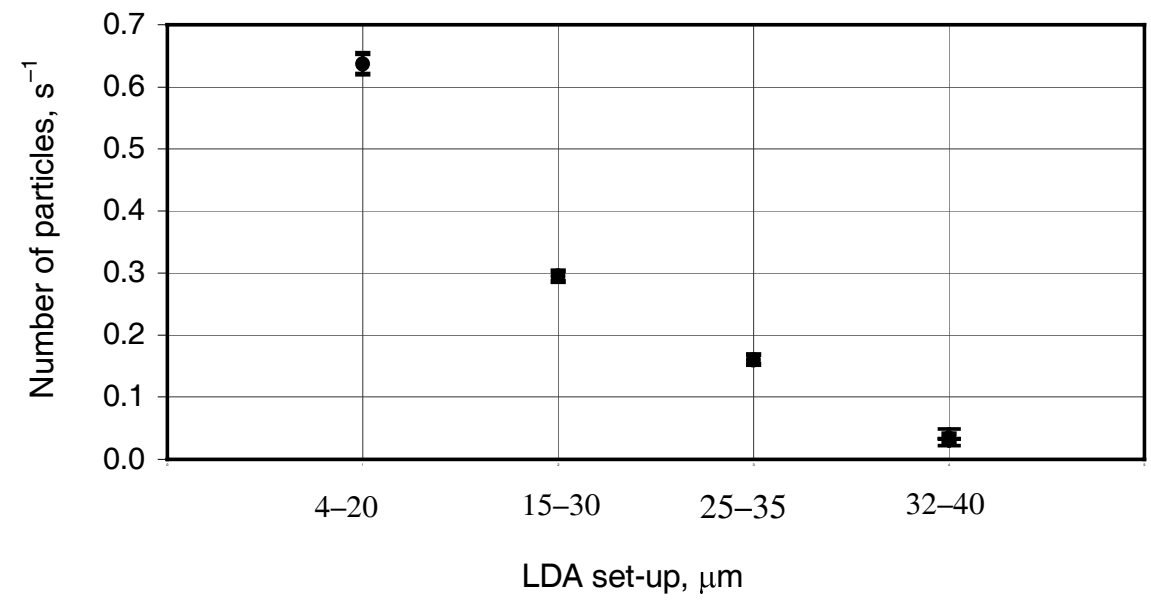

Fig. 5. Dependence of the particle concentration on the LDA set-up.

tion of particles over the size ranges determined in Section 2. The particles of the size over $40 \mu \mathrm{m}$ were not detected for any combustion regime. This testifies that particles of a large size (agglomerates) were not present in the flue gas flow.

The temperature of the flue gas is the key parameter showing the amount of soot generated under particular flame condition or combustion process. In our case the additional turbulization caused lowering of the flue gas temperature at the exit of the insulated section of the combustion zone (Fig. 6). The temperature drops due to the enhancement of heat transfer in the combustion zone $\left[{ }^{5}\right]$. This 
temperature drop (especially below $780^{\circ} \mathrm{C}$ ) under intensive turbulization conditions could be one of the reasons for the emergence of carbon mono-oxide $(\mathrm{CO})$, as it is illustrated also in Fig. 7.

Figure 8 shows the dependence of the concentration of aerosol particles and $\mathrm{CO}$ in the flue gas flow on the turbulence rate for the combustion in the medium exposed to the acoustic impact.

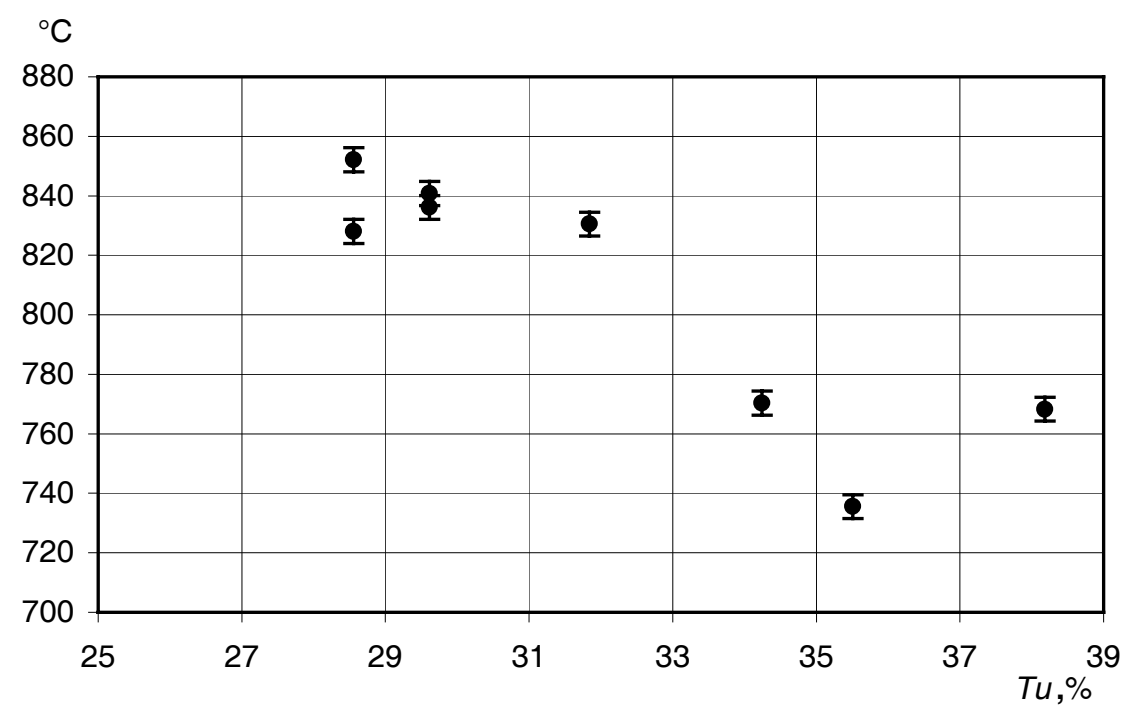

Fig. 6. Dependence of the flue gas temperature on the turbulence rate.

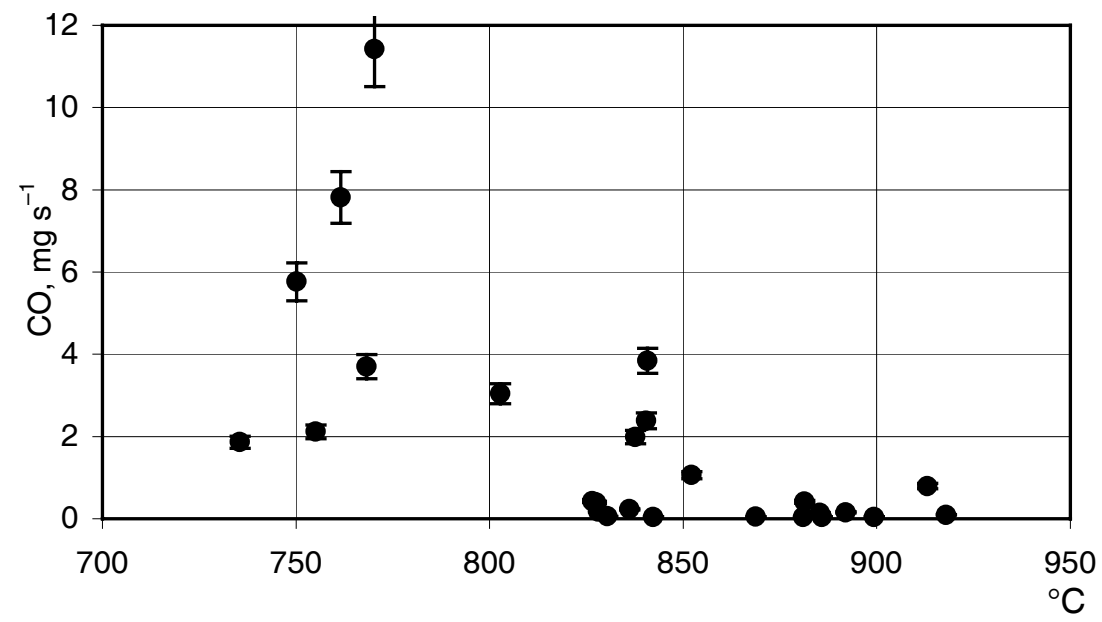

Fig. 7. The $\mathrm{CO}$ emission dependence on the flue gas temperature at the exit of the combustion chamber. 


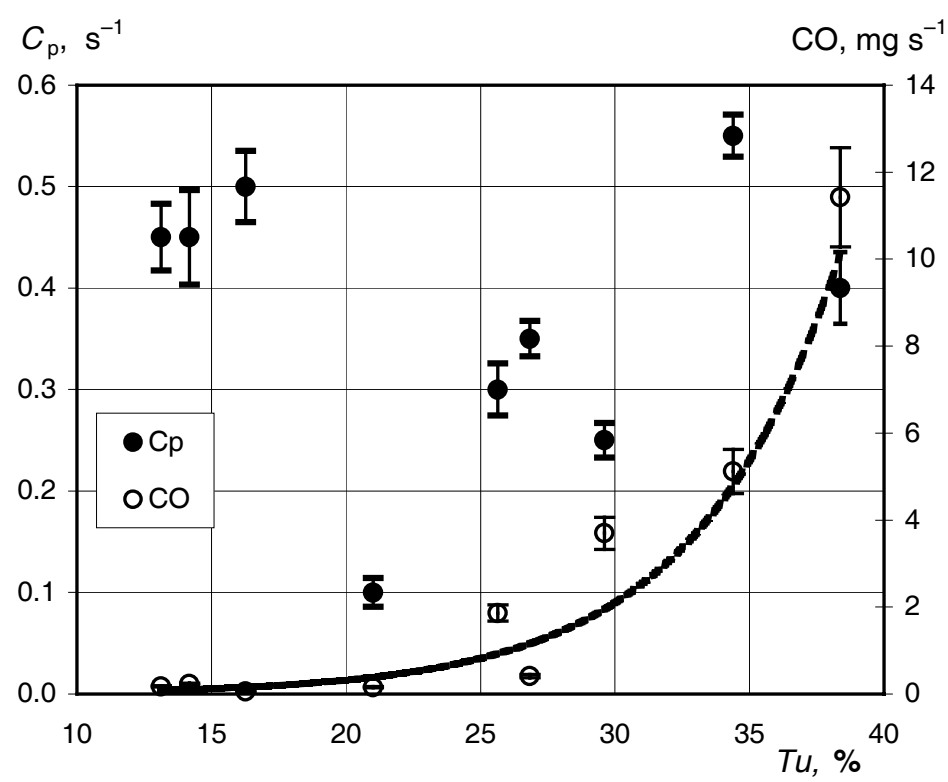

Fig. 8. The particle concentration $\left(C_{\mathrm{p}}\right)$ and $\mathrm{CO}$ content in the flue gas versus the turbulence rate.

In the combustion process there are several sources for the origination of aerosol particles - formation of soot as a result of the destruction of hydrocarbons and emergence of the sooting diffusion flame. The content of the soot particles in our experiments can be explained with the change of the flame length $\left.{ }^{5}\right]$. In our case the flame falls outside the limits of the insulated section of the combustion chamber of the test rig and that does not allow complete combustion because of the change of the temperature conditions. This phenomenon is not inherent to the studied processes, but appears because of the specific features of our test rig.

The presence of $\mathrm{CO}$ in the flue gas can be caused either by incomplete combustion or $\mathrm{CO}_{2}$ decay. As it is known, the $\mathrm{CO}_{2}$ decay starts at temperatures over $1200^{\circ} \mathrm{C}$. This temperature level exists in the initial part of the combustion chamber. For the tests with a high sound intensity, due to the increased heat transfer while the flue gas temperature is substantially lower at the exit of the combustor, combustion of products from the $\mathrm{CO}_{2}$ decay is not complete.

As it is shown in Fig. 8, the content of soot particles does not vary under conditions of the experiment, but the content of $\mathrm{CO}$ grows in flue gas with the increase of the turbulence rate. That seems to result from the $\mathrm{CO}_{2}$ decay at the exit of the insulated section of the combustion zone.

One more reason of the higher content of $\mathrm{CO}$ in flue gas in the given test may be the reforming of $\mathrm{CO}_{2}$ in the presence of the chromel wire $\left[{ }^{15}\right]$ installed along the axis of combustion chamber as one of thermocouple wires and which in this case may act as a catalyst. 


\section{CONCLUSIONS}

The method based on the LDA is suitable for studying formation of the aerosol particles directly in flue gas ducts of power equipment. This method allows to follow the formation and behaviour of aerosol particles in different combustion regimes. Monitoring of aerosol particles gives additional information about the combustion process.

During the experiments the aerosol particles of a size over $40 \mu \mathrm{m}$ were not detected for any combustion regimes of the gaseous fuel. It shows that no large agglomerates of soot particles were formed in the combustion process.

Study of the formation of aerosol particles during the combustion process made it possible to explain the effect of the increased content of $\mathrm{CO}$. In order to establish the actual reasons for the $\mathrm{CO}$ emission by low-frequency and highintensity oscillation in the combustion chamber, further investigation of the formation and behaviour of aerosol particles is needed.

\section{ACKNOWLEDGEMENT}

Financial support by the Estonian Science Foundation (grant No. 3416) is gratefully acknowledged.

\section{REFERENCES}

1. Crowe, C. T., Sommerfeld, M., and Tsuji, Y. Multiphase Flows with Droplets and Particles. CRC Press LLC, Boca Raton, 1998.

2. Ulrich, G. D. Theory of particle formation and growth in oxide synthesis flames. Combust. Sci. Technol., 1971, 47, 685-701.

3. Hussainov, M., Käär, H., Shcheglov, I., and Tiikma, T. Sonic stimulation of natural gas combustion. Proc. Estonian Acad. Sci. Eng., 1997, 3, 147-157.

4. Gutfinger, C., Vainshtein, V., and Fichman, M. Enhancement of heat and mass transfer by sound waves. Heat Transf., 1994, 6, 37-42.

5. Tiikma, T. and Vrager, A. Low frequency sonic field influence to the heat transfer in combustion chamber. In Progress in Engineering. Heat Transfer (Grochal, B., Mikielewicz, J., and Sunden, B., eds.). Proc. 3rd Baltic Heat Transfer Conference. IFFM Publishers, Gdansk, 1999, 87-94.

6. Tiwary, R., Reethof, G., and McDaniel, O. H. Acoustically generated turbulence and its effect on acoustic agglomeration. J. Acoust. Soc. Am., 1984, 76, 841-849.

7. Farias, T. L., Carvalho, M. G., and Köylü, Ü. Ö. Radiative heat transfer in soot-containing combustion systems with aggregation. Int. J. Heat Mass Transf., 1998, 41, 2581-2587.

8. Hussainov, M., Kartushinsky, A., Mulgi, A., Shcheglov, I., and Tisler, S. Properties of solid particle distribution in two-phase laminar boundary layers of various shapes and particle sedimentation. Proc. Estonian Acad. Sci. Phys. Math., 1994, 43, 237-250.

9. McLaughlin, D. K. and Tiederman, W. C. Biasing correction for individual realization laser anemometer measurements in turbulent flows. Phys. Fluids, 1973, 16, 2082-2088.

10. Klochkov, V. P., Kozlov, L. F., Potykevich, I. V., and Soskin, M. S. Handbook of Laser Anemometry. Naukova Dumka, Kiev, 1985 (in Russian).

11. Schlichting, H. Grenzschicht - Theorie. 5. Auflage. Braun - Verlag, Karlsruhe, 1965. 
12. Tyurin, J. N. and Makarov, A. A. In Statistical Analysis of Data with a Computer (Figurnov, V. E., ed.). INFRA, Moscow, 1998 (in Russian).

13. Dubnishchev, Yu. N. and Rinkevichyus, B. S. Technique of Laser Doppler Anemometry. Nauka, Moscow, 1982 (in Russian).

14. Schenck, H., Jr. Theories of Engineering Experimentation. McGraw-Hill, New York, 1971.

15. Wargadalam, V. J., Hunter, N. R., and Gesser, H. D. The carbon dioxide reforming of methane in a thermal diffusion column (TDC) hot wire reactor. Fuel Process. Technol., 1999, 59, 201-206.

\section{Aerosoolsete osakeste teke madalsagedusliku heliga stimuleeritud põlemisel}

Veera Dušenko, Medhat Hussainov, Igor Štšeglov ja Toomas Tiikma

Töös on uuritud gaasi põlemisprotsessi madalsagedusliku akustilise stimuleerimise korral. Aerosoolsete osakeste kontsentratsiooni ja kiiruse mõõtmiseks suitsugaasis kasutati selleks uuringuks kohandatud laser-Doppleri anemomeetrit. On näidatud, et nii saab otseselt mõõta aerosoolsete osakeste lokaalset kontsentratsiooni energeetilistes seadmetes. Vaadeldud on ka CO ja tahma tekkimise võimalust põlemisprotsessis väga intensiivse akustilise mõju korral. 